Research Journal of Applied Sciences 6 (6): 366-372, 2011

ISSN: $1815-932 \mathrm{X}$

(C) Medwell Journals, 2011

\title{
A Theoretic Discussion of Tourism M-commerce
}

\author{
Saleh Alqatan, Dalbir Singh and Kamsuriah Ahmad \\ Faculty of Information Science and Technology, Universiti Kebangsaan Malaysia, \\ Bangi, Selangor, Malaysia
}

\begin{abstract}
The involvement of the tourism firms in M-commerce is still in its formative years. At the present time, the use of mobile commerce in businesses is becoming a necessity to create value for different types of firms across different sectors including the tourism industry. Further, M-commerce can serve as a unique tool for the tourism industry to enhance their services which could well determine their value creation and business performance. Although, many studies exist on the adoption of M-commerce but they hardly provide any specific illustration on a successful adoption of M-commerce across various industries such as tourism. Further, it lack of sufficient knowledge about the existing services of $\mathrm{M}$-commerce that led to failure in providing the convincing suggestions to decision makers in firms to adopt new knowledge. Further, a little research has been done to explore the advantages of modern technologies like $\mathrm{M}$-commerce in similar applications for the tourism industry of developing countries. This study thus, attempts provides advanced knowledge by explaining the importance and adaption strategies of mobile commerce in the tourism industry.
\end{abstract}

Key words: M-commerce, tourism M-commerce, tourism M-commerce architecture, business performance, firms, Malaysia

\section{INTRODUCTION}

The internet stands as one of the most vital business innovations of the time (Buhalis, 2003). This colossal technological development is barring unforeseen promises of enterprise and businesses are already using the internet to communicate with customers, suppliers and partners, share product information, buy and sell and to conduct numerous daily business functions (Okoli, 2007). In addition, the internet grants a constant reserve of new opportunities for tourism organizations to offer new services and products that increase the effectiveness of their business for a lesser cost.

It also improves services that cater for tourists such as access to information, bookings as well as communication and interaction between existing service and customers (Kim, 2004). Particularly, the rapid growth of internet users has led to the emergence of a new enterprise called electronic tourism or E-tourism.

In recent times, commercialization of the Internet has driven E-Tourism (ET) to become one of the most important media for sharing business information within organizations and between business partners.

E-tourism is essentially an application of internet technology in the tourism sector (Paudel and Hossain,
2006). Internet technology is particularly critical to this sector as it adds new values in developing tourism products and services (Janssen and Cresswell, 2005). It also contributes to the promotion of competitive advantages in tourism firms (Ong and Bin, 2008). Internet technology also introduced novel technologies such as mobile commerce (M-commerce) which rapidly increased the use of wireless handheld devices in accessing the internet (Singh et al., 2006).

The evolving success and ubiquity of mobile communication precipitated a shift from E-commerce (Wired environment) to M-commerce (Wireless environment) whereby users of mobile devices are now collectively considered to be the largest potential market (Liong, 2008).

Mobile commerce (or M-commerce) is functionally defined as distance trading in essence which includes all marketing and advertising activities as well as all buying and selling activities using wireless handheld devices such as smart phones.

Concurrently, mobile tourism's potential is on the rise owing to difficulties in information access by tourists and the failure of tourism websites to meet the expectations and aspirations of tourists (Salim et al., 2010) (Fig. 1).

Corresponding Author: Saleh Alqatan, Faculty of Information Science and Technology, Universiti Kebangsaan Malaysia, Bangi, Selangor, Malaysia 
Res. J. Applied Sci., 6 (6): 366-372, 2011

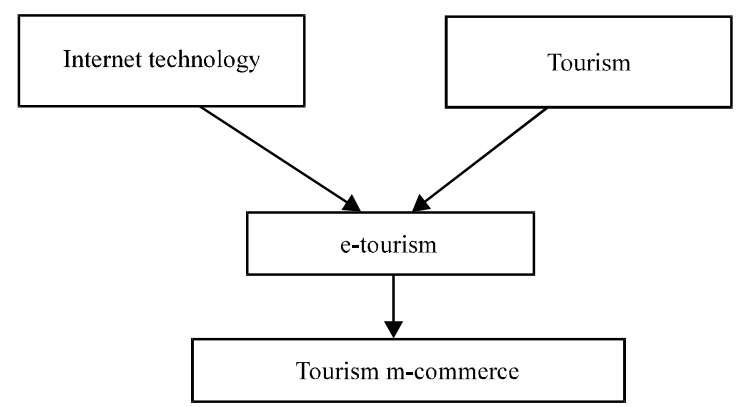

Fig. 1: Tourism M-commerce structure

\section{MOBILE COMMERCE}

The rapid growth and development of electronic commerce in the contemporary world and its application of telecommunication technology has led to the existence or introduction of mobile commerce or M-commerce (Sreenivasan and Noor, 2010). According to Ngai and Gunasekaran (2007), they found out that M-commerce is a subset of electronic commerce (E-commerce) whereby M-commerce or mobile commerce enables customers or users to buy, sell or exchange information's on goods and services by using mobile devices such as smart phone (Chew, 2006; Liu, 2005). As well as that it is considered as one of the most important topics in the area of information system and also the backbone for a lot of business firms (Anckar and D'Incau, 2002). Now a days, Mobile commerce (M-commerce) is providing new opportunities whether by mobile devices or services to the customer to communicate with the required services and give them the ability to finalize transactions through wireless networks. There is a difference partially between mobile commerce and electronic commerce due to the special characteristics and restrictions of the mobile devices and wireless networks where E-commerce focus partially on wired computing environment (Andreou et al., 2002). According to Ngai and Gunasekaran (2007) although, there are high volumes of literatures that are carried out on mobile commerce (M-commerce) but this topic still needs more research and development. M-commerce provides two major features which are: mobility and broad reach whereby the users can carry out their business transactions anywhere at any time.

Mobile commerce (M-commerce) stormed all the consumer markets of the world and it has a direct and positive effect on business activities, consumer behavior and markets whether national or global (Chew, 2006; Dai and Palvi, 2009; Lee, 2008). The usage of mobile commerce is becoming very important in this present day world where the consumers are increasingly depending on their mobile phones to access the content and services which is needed crucially. Furthermore, there are many features of mobile commerce which are creating new job

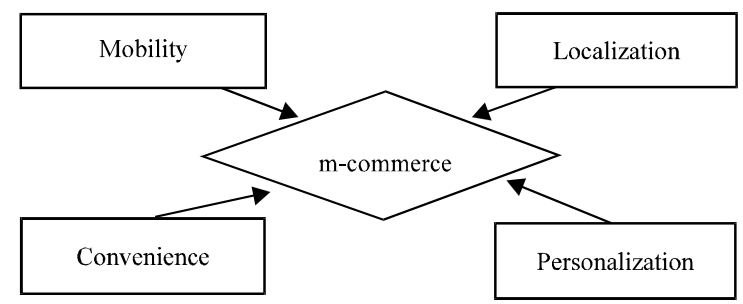

Fig. 2: Features of mobile-commerce (M-commerce)

opportunities and revenues for the organizations such as personalization, localization, ubiquity instant connectivity, time and place convenience (Azlianor et al., 2008; Grosche and Knospe, 2002). Furthermore, these features will bring many benefits to the business processes which are:

- Mobility refers to ability the users on the use provided services anywhere at any time. Highlights the importance of this feature to implement the transactions at right time and place

- Localization, give companies the ability to provide the product or service to potential customers depend on their current location by using positioning technologies such as the Global Positioning System (GPS) that provide reliable information's at time and location

- Convenience, size and usability are attributes that made the mobile devices a more convenient way than traditional computers as well as the ability to connect to internet easily and quickly

- Personalization is the unique nature of the mobile device. Unlike the traditional computers in home or public place such as internet cafe and library that may be used more than a single person

According to Tiwari et al. (2008) although, there is an evolution in the mobile commerce services and its applications in the various fields such as entertainment, travel, banking and marketing are growing increasingly but the usage mobile commerce is still slow. The mobile commerce provided many new channels to communicate and interact with potential customers which are essential in increasing the percentage of sales for the firms also given to the fact that users of mobile commerce are increasingly growing. It is expected that the mobile commerce will grow quickly more than electronic commerce in consumer markets (Barutcu, 2008; Hameed et al., 2010).

Finally, the incorporation of mobile commerce in tourism industry would be further investigated. The adoption of a new technology such as M-commerce is highly subjected to its acceptability among the stakeholders in the tourism industry (Moghadam and Assar, 2008) (Fig. 2). 


\section{TOURISM M-COMMERCE}

Information technology is contributing positively to succeed at any tourism companies where it is plays the key role in constituting the decisions and strategies of the tourism industry. Mobile-commerce being a subset of internet technology has several technology acceptance and adaption research issues that hinders its success (Lee and Connolly, 2010). According to Liang et al. (2007) and Srivastava et al. (2007), the adoption of the new mobile technology helps the services providers by improving the communication between the customer and tourism organization and plays a vital role in increasing the capacity of productivity and profitability of the organization as well. In addition, the enhancement or quick access to useful information enable tourists to access important information and tourism related services (Yan and Lihua, 2005). Business activities are considered as main part of the tourism industry due to its possibility to improve the products and services to attract a larger number of tourists and maintain their loyalty (BECA, 2008).

The tourism industry is considered as a strong contributor in the rapid growth of world economy (Aliqah and Al-Rfou, 2010). M-commerce in tourism sector becomes the main part of the tourism business worldwide (Asia-Pacific Economic Cooperation, 2002).

In addition, M-commerce has a very high potential to create value of different types in industries across almost in any sector. It is particularly applicable to a largely service based sector such as tourism. M-commerce reserves a great potential as a unique tool for the tourism industry in enhancing their services and determining the value of creation and business performance which ensures the success of $\mathrm{M}$-commerce implementation Salwani et al. (2009). This potential of M-commerce also indicates how mobile technology is the best available mechanism for developing countries to reduce operating costs, improve business processes and to provide tourism businesses with additional opportunities to sell their products or services as well as to establish partnerships with carriers, tour operators, travel agencies and national tourism offices (Mlozi et al., 2010). Therefore, the application of mobile-commerce (M-commerce) will give the customer the ability to access the internet and increase their loyalty. Today many tourism organizations make efforts in using the $\mathrm{M}$-commerce services to increase the customer's satisfaction to stay as loyal customers (Dai and Palvi, 2009).

According to Srivastava et al. (2007), mobile technology still need's the continuous research maximize its services according to the benefits they provide. The tourism industry is one of the most dynamic industries whereby it grows and change quickly as well. The mobile technology effects on the tourism industry through the development of new products and services is to satisfy the customer's requirement has becomes more and more important in achieving the goal of the organization. Besides that it also supports the competitiveness of tourism firms by providing a new offer to travelers on-location and on-demand during their travel. This causes product or service differentiation among competitors (Daghfous and Barkhi, 2009).

Finally, there are many tourism offices that have the intention of using mobile technology in order to tackle the challenges that they are facing such as communication issues and distribution of their products and services by using the low cost and simple technologies due to the fact that the current technologies have not been able to solve these problems (Mlozi et al., 2010). Adoption of mobilecommerce is the solution to some challenges that are facing the tourism industry currently where there the integration between mobile commerce, tourism and hospitality industry will be aimed to provide the convenience to their customers which is one of the basic features in mobile commerce. Table 1 shows some of the previous studies that showed the relationship between commerce and tourism, either through tourism Ecommerce or tourism M-commerce. Previous studies reveal the urgency and the importance of mobile

Table 1: Previous studies on the relationship between commerce and tourism

Title

Innovation services of tour mobile E-commerce areas

Tourism E-commerce between China and United States: A case study of ctrip and expedia

E-commerce usage and business performance in the Malaysian tourism sector: Empirical analysis

The reconfiguration of tourism value chain based on E-commerce

E-commerce adoption of travel and tourism organizations in South Africa, Keny a, Zimbabwe and Uganda

Hindrances to the development of tourism E-commerce in China

The function and evolutional model research on tourism E-commerce

A theoretic discussion of tourism E-commerce

Auctioning tourism products over mobile devices
References

Zhang and $\mathrm{Wu}(2010)$

Liu et al. (2009)

Salwani et al. (2009)

Zhao et al. (2009)

Maswera et al. (2008)

Yang et al. (2008)

Zhong (2007)

Liu (2005)

Tsamakos et al. (2002) 
commerce in the tourism industry. These studies also indicate how the tourism industry could embrace mobile technology in their daily operation while adding their business value. Thus, integration architecture should be formulated that outlines the integration of mobile technology with existing electronic commerce in the tourism industry.

\section{TOURISM M-COMMERCE ARCHITECTURE}

Organization architecture is essentially a model that effectively determines and explains the relationship between the elements involved in the integration of mobile devices, mobile technologies and the business processes therein. The integration of mobile commerce into tourism organizations requires such organization architecture for M-commerce services which would facilitate a correspondingly integrated view of strategies that enable these organizations' systems to increase profitability, reduces complexity increase effectiveness and efficiency (Hameed et al., 2010).

The tourism $\mathrm{M}$-commerce architecture defines the interaction and integration among: tourism organizations (As service and product providers), M-commerce and tourists (As clients). Research conducted on the adoption and usage of $\mathrm{M}$-commerce in various industries revealed an existing lack of integration architecture between M-commerce and the tourism industry and indicated a need for continued research in this area (Oliveira and Martins, 2010). Although, expectedly, the integration of $\mathrm{M}$-commerce can enable tourism organizations to enhance their business processes and solve many business transaction problems that they encounter (Chou and Lee, 2008). According to previous research, very little is known about the impact of such integration on the actual performance of these organizations and their processes (Janssen and Cresswell, 2005).

The key components in the successful application of mobile solutions in overcoming the challenges of an organization are the mobile device itself, wireless network connectivity, enterprise integration and most importantly, the application architecture. Although, not widely known by the masses, various existing application models are viable for mobile development purposes this viability being highly dependent on the varying characteristics of these models (Azlianor et al., 2008).

Two major challenges for many tourism organizations are to identify potential customers and to communicate with them effectively and efficiently by providing the number of products and services which would thereafter, deepen the relationship between the customer and the tourism enterprises (Christer et al., 2005). In answer to these challenges, the adoption and use of mobile technology may impart two beneficial impacts on an organization's processes, namely; improve effectiveness and efficiency of communication among the clients and the organization's staff and enable clients to obtain information and services at any time and from any place and to increase the profitability and productivity of the organization (Liang et al., 2007). Therein, the integration of mobile commerce and tourism can be a fruitful solution to the problems and challenges encountered by tourism organizations. This study puts forward tourism Mcommerce architecture (Fig. 3) whereby the components of the architecture are as follows:

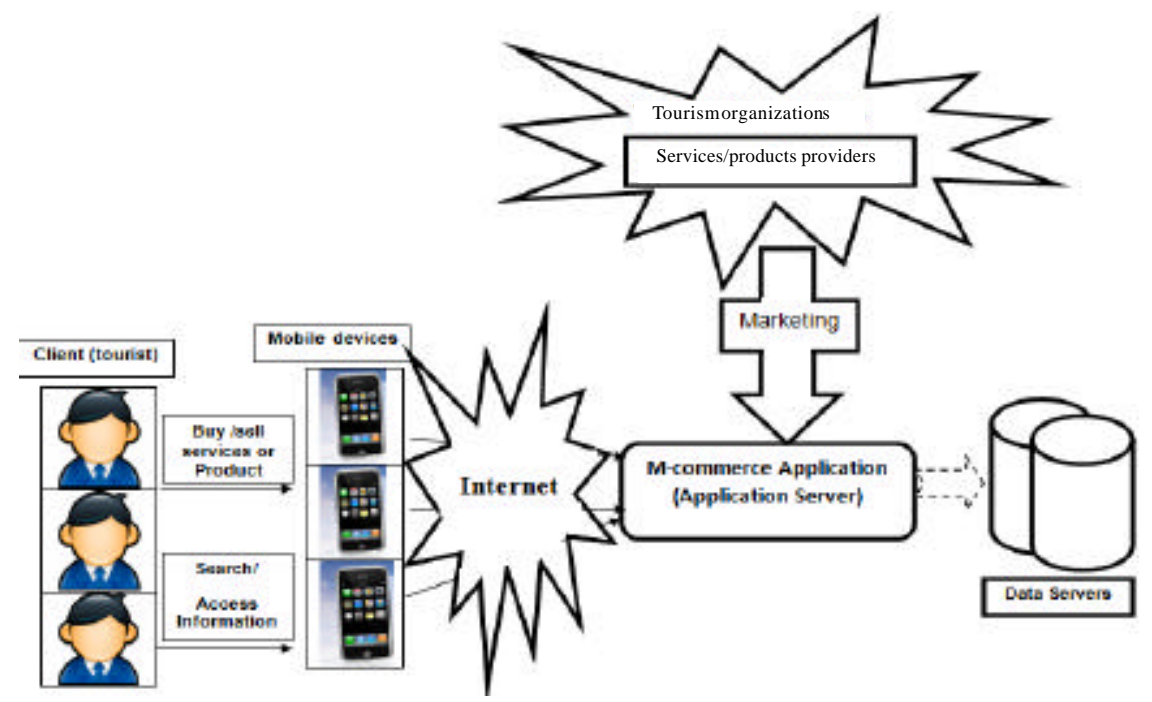

Fig. 3: Tourism M-commerce Architecture (TMA) 
The client (or tourist): Who will use their phone (Mobile device) to search and access information related to tourism and to purchase products or services provided by suppliers and service providers from among tourism organizations.

The M-commerce application: Which actually represents a tourism information network that links the tourist with tourism organizations and which plays an active role in the life cycle in the tourism mobile commerce architecture.

The service/products provider: Who offers and publishes services and products, commensurate with the needs and desires of the tourists, through the M-commerce application.

The Data Server (DS): Which represents a set of databases that contains information on available tourism services and products (From service/products providers) for the tourists.

Despite prior attempts to design a standardized architecture to integrate $\mathrm{M}$-commerce in enterprises such as tourism, there is still a need for continued research to find a more convenient architecture (Kunene and Adigun, 2003). In response to such a need this study proposes a new architecture to make M-commerce application adoption, more convenient and efficient in the tourism industry. In addition, the architecture integrates $M$ commerce with tourism organizations towards better locating services, products and information.

\section{CONCLUSION}

The research work proposes the beneficial use of new technologies in mobile commerce (M-commerce) to; improve the performance of organizations in the tourism industry, promote tourist satisfaction and gain the trust of tourists. The adoption and use of M-commerce in the tourism industry is still in its formative stage. This study advances knowledge in the field by exploring the potential of M-commerce in improving services provided by the tourism industry. M-commerce is currently growing in the tourism industry wherein the internet aids the development and enhancement of various services such as hotels, restaurants and visitors' information. Notably, the tourism and hospitality industries have illustrated how $\mathrm{M}$-commerce may develop and change the structure of an entire industry while concurrently creating new investment opportunities and enhancing business performance. However, despite existing research on mobile commerce in general this study found only a few studies on the adoption of mobile commerce across tourism industry in the developing countries. The lack of empirical research in the hospitality industry can be identified as the key explanation for the existing deficiency in knowledge of new services and as the foremost reason why tourism consistently lags behind other industries especially, in developing countries. Consequently, a great need persists for further research to understand and harness the benefits of M-commerce's usage in the tourism industry.

\section{REFERENCES}

Aliqah, K.M.A. and A.N. Al-Rfou, 2010. The role of tourism sector on economic development in Jordan during the period (1990-2008). Eur. J. Econ. Finance Admin. Sci., 2010: 173-180.

Anckar, B. and D. D'Incau, 2002. Value-added services in mobile commerce: An analytical framework and empirical findings from a national consumer survey. Proceedings of the 35th Annual Hawaii International Conference on Systems Sciences, January 7-10, 2002 , Hawaii, USA., pp: 1444-1453.

Andreou, A.S., C. Chrysostomou, C. Leonidou, S. Mavromoustakos, A. Pitsillides and G. Samaras, 2002. Mobile commerce applications and services: A design and development approach. Proceedings of the 1st International Conference on Mobile Business, July 8-9, 2002, Athens, Greece, pp: 1-9.

Asia-Pacific Economic Cooperation, 2002. Application of E-commerce strategies to small and medium sized tourism enterprises in the APEC region. http://publications.apec.org/publication-detail.php?pub_id=536.

Azlianor, A., S. Suhaizan, K. Massila and A.M. Haziq Lim, 2008. A Mobile web application architecture for generating destination-oriented LRT route. Proceeding of the International Conference on Applied Computing Conference, May 27-30, 2008, Istanbul, Turkey, pp: 242-244.

BECA, 2008. About business events. Business Event Council of Australia. http:/www.businesseventscouncil.org.au/page/aboutbr_business_events.html.

Barutcu, S., 2008. Customers attitudes towards mobile commerce and mobile marketing in consumer markets. Ege Acad. Rev., 8: 15-32.

Buhalis, D., 2003. E-Tourism, Information Technology For Strategic Tourism Management. Financial Times Prentice Hall, New Jersey, ISBN: 9780582357402, Pages: 376. 
Chew, A.A., 2006. The adoption of M-commerce in the United States: Long Beach. California State University, USA., pp: 1-32. http://www.csulb.edu/ colleges/cba/honors/thesis/documents/Anthony_ A._Chew_Thesis. pdf.

Chou, T.H. and Y.M. Lee, 2008. Integrating E-services with a telecommunication E-commerce using serviceoriented architecture. J. Software, 3: 60-67.

Christer, C., J. Carlsson and P. Walden, 2005. Mobile services for the hospitality industry. Proceedings of the 13th European Conference on Information Systems, Information Systems in a Rapidly Changing Economy, May 26-28, Regensburg, Germany.

Daghfous, A. and R. Barkhi, 2009. The strategic management of information technology in UAE hotels: An exploratory study of TQM, SCM and CRM implementations. Technovation, 29: 588-595.

Dai, H. and P.C. Palvi, 2009. Mobile commerce adoption in China and the United States: A cross-cultural study. ACM SIGMIS Database, 40: 43-61.

Grosche, S.S. and H. Knospe, 2002. Secure mobile commerce. IEEElectron. Commun. Eng. J., 14: 228-238.

Hameed, K., H. Shah, K. Ahsan and W. Yang, 2010. An enterprise architecture framework for mobile commerce. Int. J. Comput. Sci., 7: 6-12.

Janssen, M. and A.M. Cresswell, 2005. An enterprise application integration methodology for Egovernment. J. Enterp. Inform. Manage., 18: 531-547.

Kim, C., 2004. E-tourism: An innovative approach for the small and medium-sized tourism enterprises (SMTES) in Korea. OECD Reports. http://www.oecd.org/ dataoecd/56/13/34268048.pdf.

Kunene, H.P. and M.O. Adigun, 2003. Towards enterprise-component architecture for $\mathrm{M}$-commerce services. http://www.satnac.org.za/proceedings/2003/ wip/wip2/625\%20-\%20Kunene.pdf.

Lee, S. and D.J. Connolly, 2010. The impact of IT news on hospitality firm value using cumulative abnormal returns (CARs). Int. J. Hospitality Manage., 29: 354-362.

Lee, Y.H., 2008. Exploring Factors Affecting Mobile Commerce Adoption in the United States, Korea and China: The tests of Theories, Models and Cultural Differences. University of South Carolina, ISBN-13: 9780549845362, South Carolina, Pages: 357.

Liang, T.P., C.W. Huang, Y.H. Yeh and B. Lin, 2007. Adoption of mobile technology in business: A fit-viability model. Ind. Manage. Data Syst., 107: 1154-1169.

Liong, W.L., 2008. Exploring determinants of adoption of mobile commerce services. University Malaya, Kuala Lumpur, Malaysia.
Liu, S., 2005. A theoretic discussion of tourism E-commerce. Proceedings of the 7 th International Conference on Electronic Commerce, Aug. 15-17, ACM, New York, USA., pp: 1-5.

Liu, Z., J. Yang and Y. Gu, 2009. Tourism E-commerce between China and United States: A case study of ctrip and expedia. Proceedings of the International Conference on Management of E-commerce and E-government, Sept. 16-19, Shanghai, China, pp: 44-48.

Maswera, T., R. Dawson and J. Edwards, 2008. E-commerce adoption of travel and tourism organisations in South Africa, Kenya, Zimbabwe and Uganda. Telematics Inf., 25: 187-200.

Mlozi, S., F. Jing and E. Sedoyeka, 2010. Technology adoption in tourism industry: A case of wireless technology (WiMAX) for Tanzania. Proceeding of the International Conference on E-business and E-government, May 7-9, Guangzhou, China, pp: $376-379$.

Moghadam, A.H. and P. Assar, 2008. The relationship between national culture and E-adoption: A case study of Iran. Am. J. Applied Sci., 5: 369-377.

Ngai, E.W.T. and A. Gunasekaran, 2007. A review for mobile commerce research and applications. Decis. Support Syst., 43: 3-15.

Okoli, C., 2007. The internet competitive landscape: Insights from organisational ecology. Int. J. Bus. Environ., 1: 411-427.

Oliveira, T.and M.F. Martins, 2010. Firms patterns of E-business adoption: Evidence for the European Union-27. Electron. J. Inf. Syst. Eval., 13: 47-56.

Ong, J.W. and H.I. Bin, 2008. Sustainable competitive advantage through information technology competence: Resource-based view on small and medium enterprises. Commun. IBIMA, 1: 62-70.

Paudel, B. and A. Hossain, 2006. Fuzzy based decision support system for E-tourism investment risk analysis. East-West Euro-Asia Collaborations and Networking in Information Engineering System Technology, pp: 1-6. http://eastwest.inf.brad.ac.uk/ document/publication/Paudel-SKIMA.pdf.

Salim, J., A.B. Arifin and O.A. Puade, 2010. Mobile tourism directory. Proceedings of the International Symposium on Information Technology, June 15-17, Kuala Lumpur, Malaysia, pp: 1-5.

Salwani, M.I., G. Marthandan, M.D. Norzaidi and S.C. Chong, 2009. E-commerce usage and business performance in the Malaysian tourism sector: Empirical analysis. Inform. Manage. Comput. Security, 17: 166-185. 
Singh, N., G. Fassott, M.C.H. Chao and J.A. Hoffmann, 2006. Understanding international web site usage: A cross-national study of German, Brazilian and Taiwanese online consumers. Int. Marketing Rev., 23: 83-97.

Sreenivasan, J. and M.N.M. Noor, 2010. A conceptual framework on mobile commerce acceptance and usage among Malaysian consumers: The influence of location, privacy, trust and purchasing power. WSEAS Trans. Inf. Sci. Appl., 7: 661-670.

Srivastava, A., R. Tassabehji and J. Wallace, 2007. Incorporating $\mathrm{M}$-commerce into organizational strategy: A case study in the tourism sector. Proceedings of the 13th Americas Conference on Information Systems, Aug. 10-12, Keystone, CO., USA.

Tiwari, R., S. Buse and C. Herstatt, 2008. From electronic to mobile commerce opportunities through technology convergence for business services. CACCI J., 1: 1-12.

Tsamakos, A., G.M. Giaglis and P. Kourouthanassis, 2002. Auctioning tourism products over mobile devices. Proceedings of the 1st International Conference on Mobile Commerce, July 2002, Athens, Greece, pp: $1-10$.
Yan, C. and H. Lihua, 2005. Mobile business applications adoption model based on the concepts of task/technology fit. Proceedings of the International Conference on Services Systems and Services Management, June 13-15, Shanghai, China, pp: 1346-1350.

Yang, L., X. Liu and C. Xu, 2008. Hindrances to the development of tourism E-commerce in China. Proceedings of the International Symposium on Electronic Commerce and Security, Aug. 3-5, Guang zhou, China, pp: 588-591.

Zhang, X.J. and C. Wu, 2010. Innovation services of tour mobile E-commerce areas. Proceedings of the International Conference on Internet Technology and Applications, Aug. 20-22, Shanghai, China, pp: 1-3.

Zhao, L., G. Cao and M. Liu, 2009. The reconfiguration of tourism value chain based on E-commerce. Proceedings of the International Conference on Management of E-commerce and E-government, Sept. 16-19, Nanchang, China, pp: 522-525.

Zhong, C.D., 2007. The function and evolutional model research on tourism E-commerce: The travel and tourism management and investment resource. Chin. Bus. Rev., 6: 1-1. 